\title{
RESEARCH
}

Open Access

\section{Prevalence and associated factors of self- treatment behaviour among different elder subgroups in rural China: a cross-sectional study}

Wanchun Xu, Zhong Li, Zijing Pan, Ruibo He and Liang Zhang ${ }^{*}$ (1)

\begin{abstract}
Background: Self-treatment is a common and widespread behaviour, of which the risks are multiplied in old age. However, the determinants of self-treatment among elders in rural China remain unclear. This study aims to explore the prevalence and associated factors of self-treatment among elders in rural China, trying to discover the vulnerable groups as well as the service gaps among the rural elders.
\end{abstract}

Methods: Based on a multi-stage stratified random sampling method, a cross-sectional household survey was conducted among 30 villages in Sinan County, an impoverished county in western China. Data were collected through a household-individual combined questionnaires. The analysis was restricted to elders who reported illness within the last 2 weeks, and the final sample size was 330 (individuals). Bivariate and multiple logistic regression analysis were performed in the whole sample group and four subgroups to obtain the prevalence ratios regarding the associated factors.

Results: In the present study, 35.2\% of the elders with illness within the last 2 weeks reported self-treatment. The variables associated with self-treatment in the whole sample group were health status (OR 6.75, 95\% Cl 1.93-23.60), recent alcohol consumption (OR $0.42,95 \% \mathrm{Cl} 0.21-0.83$ ) and the utilisation of family practice services (OR $0.59,95 \% \mathrm{Cl} 0.36-0.96)$; the same predictors were found in the subgroup of elders with chronic diseases. No significant predictors were found in the subgroup of elders without chronic diseases. Empty-nest elders with higher affinity to traditional Chinese medicine (OR $0.39,95 \% \mathrm{Cl} 0.18-0.86$ ) or drinking alcohol recently (OR $0.28,95 \% \mathrm{Cl} 0.09-0.82)$ were less likely to self-treat, while the non-empty-nest elders who were no less than 75 years old $(\mathrm{OR} 3.10,95 \% \mathrm{Cl} 1.33,7.22)$ or at better health status (OR 9.20, 95\%Cl 1.73-48.75) were more likely to self-treat.

Conclusion: Self-treatment was prevalent among the elders in rural China. Better health status, no recent alcohol consumption and no utilisation of family practice are associated with self-treatment among rural elders. Older elders in the non-empty nest group were more likely to self-treat, while the empty-nest elders with self-care habits in traditional Chinese medicine were less likely to self-treat. Deeper understanding of the self-treatment behaviour among rural elders may provide insights for identifying the potential service gaps and developing improvement strategies in the health care delivery system for the elderly in China.

Keywords: Self-treatment, The elderly, Rural China, Family practice, Empty nest

\footnotetext{
* Correspondence: zhanglianghust@126.com

School of Medicine and Health Management, Tongji Medical College, Huazhong University of Science and Technology, No 13 Hangkong Road, Qiaokou District, Wuhan 430030, Hubei, China
}

(c) The Author(s). 2020 Open Access This article is licensed under a Creative Commons Attribution 4.0 International License, which permits use, sharing, adaptation, distribution and reproduction in any medium or format, as long as you give appropriate credit to the original author(s) and the source, provide a link to the Creative Commons licence, and indicate if changes were made. The images or other third party material in this article are included in the article's Creative Commons licence, unless indicated otherwise in a credit line to the material. If material is not included in the article's Creative Commons licence and your intended use is not permitted by statutory regulation or exceeds the permitted use, you will need to obtain permission directly from the copyright holder. To view a copy of this licence, visit http://creativecommons.org/licenses/by/4.0/ The Creative Commons Public Domain Dedication waiver (http://creativecommons.org/publicdomain/zero/1.0/) applies to the data made available in this article, unless otherwise stated in a credit line to the data. 


\section{Background}

Progressive ageing has raised a great challenge to the healthcare system in many countries. As the WHO advocated, the fragmented healthcare systems need to be transformed to provide integrated healthcare services to respond to the needs of the elderly [1]. Some developed countries, such as the UK, Australia and Canada, have established relatively complete healthcare delivery systems for the elderly [2]. However, the availability of affordable and convenient medical care to elders in low and middle income countries (LMICs) is still far from being satisfactory [3]. Costly medical expense, inconvenience to medical visits, distrust on the healthcare system and other social changes lead to the non-use of health services or selftreatment behaviour of the elderly [4-6]. Due to the increasing drug availability and the permissive regulation of drug retailing, the latter choice is more common in LMICs, especially in underdeveloped rural areas [7].

Self-treatment refers to the scenario where a person uses unprescribed drugs or other approaches to cope with illness conditions' [8]. Self-medication is the most common form of self-treatment, which has been widely discussed in the fields of health behaviours and drug management $[9,10]$. According to the WHO, selfmedicine refers to the use of medicine by individuals to treat self-recognised illness or symptoms [11]. The forms of self-medication included over-the-counter (OTC) medicine use, prescription medication purchased using expired and non-refillable prescriptions, leftover drugs from old prescriptions, prescription medications offered by family and friends, and so on [12]. Besides selfmedication, there are other common approaches of selftreatment including massage, physiotherapy and so on.

Self-treatment is highly prevalent among the elderly in some countries. A systematic review revealed that the prevalence of self-medication among elders varies from 20 to $60 \%$ in most studies [9]. The data of the China National Health Survey (CNHS) in 2013 suggested that the prevalence of self-treatment among the elderly is $44.2 \%$, with a slight difference between urban (43.1\%) and rural $(45.8 \%)$ areas [13]. Although self-treatment can increase the individuals' availability of medical help and reduce the pressure on the healthcare system, several risks are involved in self-treatment, such as incorrect selfdiagnosis, delays in seeking for professional help and adverse drug reactions (ADRs) due to the inappropriate use of medicine [10, 14]. Some previous studies have shown that elders are at higher risk for illness than other age groups; thus, elders are prone to greater consumption of drugs and higher risk of inappropriate drug use [15]. Moreover, inappropriate use of drug would result in more serious ADRs for the elders due to age-related changes in the pharmacokinetics and pharmacodynamics of drugs [16].
An official or agreed definition of 'self-treatment' is still lacking worldwide. The present study is based on the data from a household survey conducted in a poor rural county in western China. The definition of selftreatment in the questionnaires referred to the China National Health Survey (CNHS) and other previous studies. In the CNHS, 'self-treatment' is defined as 'taking some drugs and/or other remedies, or having a massage and/or physiotherapy rather than visiting a physician when experiencing symptoms or complaints during the two weeks preceding the survey' [17]. Based on the definition of CNHS, self-treatment is defined in the questionnaire of the present study as 'taking drugs and/or other physiotherapy approaches without physicians' advice to cope with the symptoms or complaints during the two-week period preceding the survey'. According to the review on previous studies, the behaviours considered as self-treatment in the present study includes purchasing OTC medicine with self-diagnosis from drug stores, using leftover drugs or purchasing drugs from expired prescription, taking the prescription drugs given by the friends or relatives, and receiving acupuncture, massaging or other physiotherapy treatments at home or in non-medical institution.

Previous studies have examined the potential determinants of self-medication and self-treatment behaviour among the elderly. Female sex, visits to pharmacists, depression, functional dependency, recent hospitalisation, oral pain and restriction of physical inactivity are positively associated with self-medication, whereas medical appointments, married status, use of health services, satisfaction with living arrangement, living in institutional settings and private health plans are negatively related to the choice of self-medication [9]. Long-term illness is broadly proven to be associated with the higher possibility of self-medication [12] or self-treatment [17]. The decision to self-treat involves an interaction between internal dynamic and external strengthening mechanisms, including individual, household, accessibility and medical insurance system factors [17]. However, the factors examined in studies with Chinese settings mostly included the socio-demographic characteristics and health status of individuals. The roles of the health-care delivery system and the social changes [5] were rarely given attention. This knowledge gap may result in an incomprehensive understanding of the mechanisms underlying the self-treatment behaviour of the elderly in current China, as well as the identification of the vulnerable groups.

According to the literature review, several factors in the setting of rural China may contribute to the better understanding of the knowledge gaps mentioned above. Firstly, the condition of the family practice system may influence the rural elders' health-seeking behaviour, 
including their resorting to self-treatment. The family practice contract service has been implemented in China in the new round of the healthcare reform since 2009, aiming to build a closer relationship between the residents and family practice physicians, which would help doctors improve the efficacy and comprehensiveness of primary care services [18]. However, the effect of the family practice on some of the residents' health-seeking behaviour in China has not been examined yet. Secondly, as for the social changes, China is experiencing rapid ageing and urbanisation, and the number of empty-nest elders who are living away from their children is increasing in rural areas. The impact of family caregivers on the elders' medical decision-making has been well documented [19-22]. A study in China indicated that empty-nest seniors have a higher non-use rate of healthcare services [23]. The empty-nest effect on the elders' self-treatment remains unknown. Thirdly, the role of traditional Chinese Medicine (TCM) is worthy of attention. The TCM theory is often used to guide selfcare practices in the daily life of Chinese people [24]. However, research published in both English and Chinese presented a shortage of discussion on the selftreatment issue from the perspective of TCM [25].

In this study, we explored the factors associated with self-treatment among the elderly using the data of a household survey conducted in a poor county in rural western China. The variables related to the knowledge gaps mentioned above were considered in the study design, which distinguishes this study from previous ones. Considering that the long-term illness [26] and condition of the caregivers [21] may influence the elders' health-seeking pattern, we conducted the analysis separately in the whole sample group and four subgroups (i.e. elders with chronic diseases, elders without chronic diseases, empty-nest elders and non-empty-nest elders). From the perspective of universal health coverage, deeper understandings of the self-treatment issue among rural elders are crucial to discovering not only the potential vulnerable groups who may be at higher risk of inequality to health service access [23], but also the service gaps [17] in the present health care system. These findings will be constructive for the improvement of the healthcare delivery system for the elderly.

\section{Methods}

\section{Study design and population}

This study was based on the data from a national survey to assess the residents' healthcare needs, which is a part of a research on the capacity-building of the primary care system in China. The national household survey mentioned above was carried out with general population in four counties/districts across China, including the two districts in urban area (Futian in eastern China,
Xiling in central China) and two counties in rural area (Dangyang in middle China, Sinan in western China). With 489 administrative villages [27] and the population size of 499,398 [28], Sinan county is an impoverished county on the list of national-level poverty-stricken counties recognised by the State Council of China. Eighteen minority ethnic groups are also living in the county of Sinan [29]. The data collected in Sinan were analysed in this article. The household survey in Sinan was conducted in July 2018.

A multi-stage stratified random sample was drawn to conduct one-to-one interviews, and the design effect was set at 2.5 in the sample size calculation. With an allowable error for significance level of 0.05 and the incidence of chronic diseases among the population $(21.338 \%)$ according to the fifth CNHS [13], the minimum sample size was calculated to be 3584 individuals in 1235 families in 30 villages in each study centre. In the first stage, five towns were randomly selected according to the distance to the county hospital. In the second stage, six villages were randomly selected in each town according to the distance to the township hospitals. In case of refusal or closed household, as well as the deletion of some defective questionnaires, extra families were included in the sample to make sure that at least 42 families were effectively interviewed in each village. All the sampled families were systematically selected in the rosters of residents from the village councils. All the members of the sampled families were investigated. Finally, 3983 individuals in 1355 households in 30 villages were investigated in Sinan. All the investigators were previously trained. In the quality control procedure, the questionnaires were audited by the experienced supervisors at the end of the investigation every day. The defective questionnaires were complemented by phone, and those failed to be complete were dropped. Referring to the previous studies, our analysis was restricted to the elders ( $\geq 60$ years old, 1303 individuals in total) who reported the presence of illness during the two-week period before they were interviewed (338 individuals in total). Those who did not answer some of the variables in the present study were excluded from the analysis, and the final sample size was 330 individuals.

This study was approved by the Ethics Committee of Tongji Medical College, Huazhong University of Science and Technology (IORG No: IORG0003571).

\section{Materials and variables}

Data were collected through household-individual combined questionnaires, including basic information of families, individual demographic background, health condition, health habits and utilisation of health care. Those reporting any one of the following situations in 
the 2 weeks leading up to interview were considered as having illness or discomfort in the previous 2 weeks: 1 ) visiting the medical institution due to the diseases or injuries; 2) taking drugs or other complementary physiotherapy due to the diseases or injuries; 3) absence from work or study or resting in bed for at least 1 day due to the discomfort [13]. Those who had illness or discomfort but had not taken any actions mentioned in the three categories above were not included in the analysis, such as the elders in stable condition of chronic diseases or those with minor discomfort, who did not need any medical help or rest.

To identify individuals' self-treatment behaviour, those who had reported illnesses or discomfort in the past 2 weeks were asked to answer the following question: 'How did you treat your illness in the past two weeks?' The response options were: 1 ) self-treatment (self-medicine or other approaches); 2) outpatient visit; 3) hospitalisation; 4) no treatment. The first choice was considered as 'self-treatment'. Those practised self-medicine but got the medicine from the township hospitals or general hospitals were considered as being under treatment with doctors' instruction, and were excluded from the subjects of self-treatment. All the respondents were informed of the definition and the specific forms of selftreatment in this study mentioned above, which was written in the booklets of guidance for the investigators. Thus, a new dependent variable was created to determine if a person practises self-treatment (self-treatment versus non-self-treatment).

All socio-demographic variables were dichotomised, including (1) gender (male and female), (2) age (6074 or $\geq 75$ ), (3) in poverty (yes or no), (4) illiteracy (yes or no) and (5) the condition of family caregivers (empty-nest or non-empty-nest). The identification system of the poor families is well-developed and strict in the welfare system in China [30]. The families with annual household income per capita below the standard of the poverty in local areas, including the vulnerable groups (elders, disabled persons and minors) with neither income nor supporters, will be identified as some kind of 'poor families' ('Dibao $\mathrm{Hu}$ ', 'Wubao $\mathrm{Hu}$ ' or 'Pinkun $\mathrm{Hu}^{\prime}$ ) by the local government [31]. These officially-recognised poor family were considered as poverty population in the present study. Empty-nest elders referred to those who live alone (empty-nest singles) or with a spouse (empty-nest couples) [23]. The EQ-5D-3 L (three-level EuroQol five-dimensions) instrument was applied to access the respondents' health status. The time trade-off (TTO) technique was one of the methods for evaluating the tradeoffs between the quality of life and length of life, which can be used to generate the value set of the EQ-5D-3 L instrument [32]. The time trade-off value for each respondent can be calculated to quantify the respondent's health status, based on the scores of the five dimensions (mobility, self-care, usual activities, pain/discomfort, and anxiety/depression) in the instrument. The calculating model developed by Liu etc. for Chinese people was used in the present study [33]. The TTO values ranged from -0.149 to 1 , and higher values represent better health status. Presence of chronic diseases was also used as a variable to describe the elders' health condition. Variables of health habits include (1) self-care in TCM (yes or no) and (2) recent alcohol consumption (yes or no). Self-care in TCM includes massaging, emotional therapy, dietary supplement usage, traditional sports therapy and other supplementary approaches to remain healthy and prevent diseases in daily life as the philosophy of TCM suggests [34]. It should be noted that self-care differed from self-treatment in the present study. Selftreatment was applied to cope with a certain disease that was recorded in the interview, while self-care was practised to promote general health [11]. Recent alcohol consumption refers to drinking alcohol at least once a week in the previous 6 months and more. Variables of the healthcare delivery system include (1) distance to the nearest medical institution $(<1,2-3$, $>3 \mathrm{~km}$ ) and (2) utilisation of family practice services (yes or no). The utilisation of family practice services refers to the fact that the elders who had signed the contracts with the family doctors in the local primary care system have used one or more services in the contracts, including personal health education and instruction, personal medical care, personal health management in TCM, health management for special groups, referral service and so on.

The untreated rate of the people with illness in the previous 2 weeks, as well as the most frequent selftreated illnesses and the disease-specific self-treatment rate, were also calculated in this study.

\section{Statistical analysis}

Pearson's chi-square test was conducted in the descriptive analysis of the sample characteristics. The prevalence of self-treatment were estimated for each of the classified variables in the whole sample and four subgroups. The proportion and respective confidence intervals of $95 \%(95 \% \mathrm{CI})$ were reported. Statistical analysis was carried out using bivariate regression analysis, which not only assessed the significant difference but also reported the effect size in the form of prevalence ratios (crude odds ratios). Additionally, five multiple logistic regression models that included all variables were generated to estimate the independent effect of each variable on selftreatment, one for the whole sample and four for 
subgroups. The adjusted odds ratios, 95\% confidence interval $(95 \% \mathrm{CI})$ and $p$-value were reported. Data were analysed using Stata version 14.0. Statistical significance was set at $P<0.05$.

\section{Results}

\section{Characteristics of subjects}

The characteristics of subjects were presented in Table 1. Approximately $25.9 \%$ of the elders reported the presence of illness within the past 2 weeks before the investigation. The prevalence of self-reported chronic diseases among the elders reporting illness or discomfort in the previous 2 weeks was $74.2 \%$. Nearly half of the subjects (46.4\%) were empty-nest elders. Elders with chronic diseases were more likely to have the habits of self-care in TCM in daily life than the elders without chronic diseases $(68.2 \%$ vs. $51.8 \%, p=0.01)$. There were less older elders among the empty nest ones $(11.1 \%$ vs $19.2 \%, p=0.04)$. The non- empty nest elders were more likely to utilize the family practice $(54.8 \%$ vs $40.5 \%, p=0.01)$.

\section{Prevalence of self-treatment and bivariate analysis}

The prevalence of self-treatment was 35.2\% (95\% CI $30.0,40.6 \%$ ) among the subjects (Table 2). In addition, the prevalence of untreated cases was $5.0 \%$. The most common self-treated illnesses included cold, hypertension, intervertebral disk disease and unknown illness (symptoms or discomfort of which the diagnosis or reasons remain unknown), of which the rates of self-treatment were 41.6, 24.0, 27.9 and 55.0\%, respectively.

Across the whole sample, the prevalence of selftreatment regarding variables and results of the bivariate analysis are presented in Table 2 . The female elders were more likely to self-treat their illness (OR 1.70 ; $95 \%$ CI $1.07-2.69)$. The population groups of

Table 1 characteristics of elders reporting illness or discomfort in the previous two weeks

\begin{tabular}{|c|c|c|c|c|c|c|c|c|c|c|c|}
\hline \multirow[t]{3}{*}{ variables } & & \multirow{2}{*}{\multicolumn{2}{|c|}{$\begin{array}{l}\text { Total } \\
N=330\end{array}$}} & \multirow{2}{*}{\multicolumn{2}{|c|}{$\begin{array}{l}\text { Non-NCD elders } \\
N=85\end{array}$}} & \multirow{2}{*}{\multicolumn{2}{|c|}{$\begin{array}{l}\text { NCD elders } \\
N=245\end{array}$}} & \multirow{2}{*}{\multicolumn{2}{|c|}{$\begin{array}{l}\text { Non-empty nest } \\
N=177\end{array}$}} & \multirow{2}{*}{\multicolumn{2}{|c|}{$\begin{array}{l}\text { Empty nest } \\
N=153\end{array}$}} \\
\hline & & & & & & & & & & & \\
\hline & & $n$ & $\%$ & $n$ & $\%$ & $n$ & $\%$ & $n$ & $\%$ & $n$ & $\%$ \\
\hline \multicolumn{12}{|c|}{ Socio-demographic status } \\
\hline \multirow[t]{2}{*}{ Gender } & men & 156 & $47.3 \%$ & 35 & $41.2 \%$ & 121 & $49.4 \%$ & 79 & $44.6 \%$ & 77 & $50.3 \%$ \\
\hline & women & 174 & $52.7 \%$ & 50 & $58.8 \%$ & 124 & $50.6 \%$ & 98 & $55.4 \%$ & 76 & $49.7 \%$ \\
\hline \multirow[t]{2}{*}{ Age } & $60-74$ & 279 & $84.5 \%$ & 68 & $80.0 \%$ & 211 & $86.1 \%$ & 143 & $80.8 \%$ & 136 & $88.9 \%$ \\
\hline & $\geq 75$ & 51 & $15.5 \%$ & 17 & $20.0 \%$ & 34 & $13.9 \%$ & 34 & $19.2 \%$ & 17 & $11.1 \%$ \\
\hline \multirow[t]{2}{*}{ Poverty } & yes & 103 & $31.2 \%$ & 23 & $27.1 \%$ & 80 & $32.7 \%$ & 53 & $29.9 \%$ & 50 & $32.7 \%$ \\
\hline & no & 227 & $68.8 \%$ & 62 & $72.9 \%$ & 165 & $67.3 \%$ & 124 & $70.1 \%$ & 103 & $67.3 \%$ \\
\hline \multirow[t]{2}{*}{ Empty-nest } & yes & 153 & $46.4 \%$ & 43 & $50.6 \%$ & 110 & $44.9 \%$ & - & - & - & - \\
\hline & no & 177 & $53.6 \%$ & 42 & $49.4 \%$ & 135 & $55.1 \%$ & - & - & - & - \\
\hline \multirow[t]{2}{*}{ Illiteracy } & yes & 143 & $43.3 \%$ & 36 & $42.4 \%$ & 107 & $43.7 \%$ & 81 & $45.8 \%$ & 62 & $40.5 \%$ \\
\hline & no & 187 & $56.7 \%$ & 49 & $57.6 \%$ & 138 & $56.3 \%$ & 96 & $54.2 \%$ & 91 & $59.5 \%$ \\
\hline \multicolumn{12}{|l|}{ Health status } \\
\hline \multirow[t]{2}{*}{ Chronic diseases } & yes & 245 & $74.2 \%$ & - & - & - & - & 135 & $76.3 \%$ & 110 & $71.9 \%$ \\
\hline & no & 85 & $25.8 \%$ & - & - & - & - & 42 & $23.7 \%$ & 43 & $28.1 \%$ \\
\hline \multicolumn{12}{|l|}{ Health behaviors } \\
\hline \multirow[t]{2}{*}{ Self-care in TCM } & yes & 211 & $63.9 \%$ & 44 & $51.8 \%$ & 167 & $68.2 \%$ & 112 & $63.3 \%$ & 99 & $64.7 \%$ \\
\hline & no & 119 & $36.1 \%$ & 41 & $48.2 \%$ & 78 & $31.8 \%$ & 65 & $36.7 \%$ & 54 & $35.3 \%$ \\
\hline \multirow[t]{2}{*}{ Drinking alcohol } & yes & 71 & $21.5 \%$ & 16 & $18.8 \%$ & 55 & $22.4 \%$ & 36 & $20.3 \%$ & 35 & $22.9 \%$ \\
\hline & no & 259 & $78.5 \%$ & 69 & $81.2 \%$ & 190 & $77.6 \%$ & 141 & $79.7 \%$ & 118 & $77.1 \%$ \\
\hline \multicolumn{12}{|l|}{ Health service } \\
\hline \multirow[t]{3}{*}{ Distance $^{a}$} & $<1 \mathrm{~km}$ & 190 & $57.6 \%$ & 49 & $57.6 \%$ & 141 & $57.6 \%$ & 104 & $58.8 \%$ & 86 & $56.2 \%$ \\
\hline & $2-3 \mathrm{~km}$ & 103 & $31.2 \%$ & 26 & $30.6 \%$ & 77 & $31.4 \%$ & 59 & $33.3 \%$ & 44 & $28.8 \%$ \\
\hline & $>3 \mathrm{~km}$ & 37 & $11.2 \%$ & 10 & $11.8 \%$ & 27 & $11.0 \%$ & 14 & $7.9 \%$ & 23 & $15.0 \%$ \\
\hline \multirow[t]{2}{*}{ Family practice ${ }^{b}$} & yes & 159 & $48.2 \%$ & 37 & $43.5 \%$ & 122 & $49.8 \%$ & 97 & $54.8 \%$ & 62 & $40.5 \%$ \\
\hline & no & 171 & $51.8 \%$ & 48 & $56.5 \%$ & 123 & $50.2 \%$ & 80 & $45.2 \%$ & 91 & $59.5 \%$ \\
\hline
\end{tabular}


Table 2 prevalence and prevalence ratios of self-treatment regarding associated factors

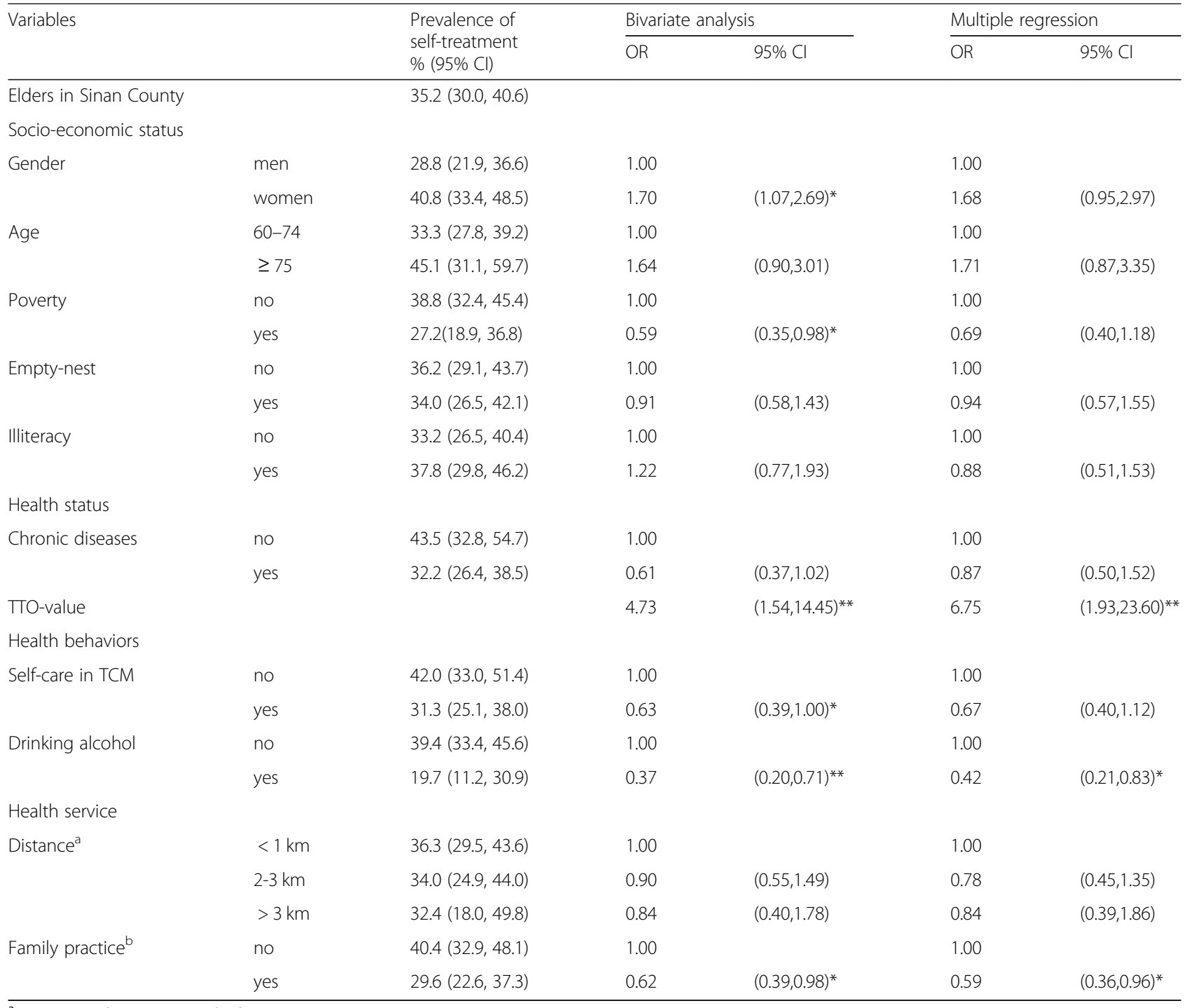

aistance to the nearest medical institution

${ }^{b}$ Utilization of family practice service

${ }^{*} P<0.05 ;{ }^{* *} P<0.01$

lower proportion of self-treatment included elders in poverty (OR $0.59,95 \%$ CI $0.35-0.98$ ), elders with recent alcohol consumption (OR 0.37 , 95\% CI 0.20 0.71 ) and elders who utilise family practice services (OR 0.62, 95\% CI 0.39-0.98). Elders who have higher TTO-value are more likely to self-treat $(\mathrm{OR}=4.73$, 95\% CI 1.54-14.45).

However, the variables with significant differences in rates of self-treatment varied among different subgroups. No significant determinants were observed in the subgroup of the elders without chronic diseases, while the results in the group of elders with chronic disease were similar to those in the whole sample groups (Table 3). In the subgroup of non-empty-nest elders, the older elders (no less than 75 years old) were more likely to self-treat (OR 3.10, 95\% CI 1.33 7.22) (Table 4). In the subgroup of empty-nest elders, the proportion of elders who self-treated was lower in those with chronic diseases than their counterpart (OR 0.47, 95\% CI 0.23-0.98) (Table 4).

\section{Logistic regression}

After adjustments, in the whole sample group, higher TTO value (OR 6.75, 95\% CI 1.93-23.60) were positively associated with self-treatment with larger effect size, while the habit of drinking alcohol (OR 0.42, 95\% CI $0.21-0.83$ ) and the utilization of family practice (OR $0.59,95 \%$ CI $0.36-0.96)$ were negatively associated with self-treatment (Table 2). 
Table 3 Comparison of prevalence and prevalence ratios between elders with and without chronic diseases

\begin{tabular}{|c|c|c|c|c|c|c|c|c|c|c|c|}
\hline \multirow[t]{3}{*}{ variables } & & \multicolumn{5}{|l|}{ Non-NCD group } & \multicolumn{5}{|l|}{ NCD population } \\
\hline & & \multirow{2}{*}{$\begin{array}{l}\text { Prevalence of } \\
\text { self-treatment } \\
\%(95 \% \text { Cl) }\end{array}$} & \multicolumn{2}{|c|}{ Bivariate analysis } & \multicolumn{2}{|c|}{ Multiple regression } & \multirow{2}{*}{$\begin{array}{l}\text { Prevalence of } \\
\text { self-treatment } \\
\%(95 \% \mathrm{Cl})\end{array}$} & \multicolumn{2}{|c|}{ Bivariate analysis } & \multicolumn{2}{|c|}{ Multiple regression } \\
\hline & & & OR & $95 \% \mathrm{Cl}$ & $\mathrm{OR}$ & $95 \% \mathrm{Cl}$ & & OR & $95 \% \mathrm{Cl}$ & OR & $95 \% \mathrm{Cl}$ \\
\hline \multicolumn{12}{|c|}{ Socio-economic status } \\
\hline \multirow[t]{2}{*}{ Gender } & men & $34.3(19.1,52.2)$ & 1.00 & & 1.00 & & $27.3(19.6,36.2)$ & 1.00 & & 1.00 & \\
\hline & women & $50.0(35.5,64.5)$ & 1.92 & $(0.79,4.67)$ & 1.72 & $(0.50,5.91)$ & $37.1(28.6,46.2)$ & 1.57 & $(0.92,2.70)$ & 1.76 & $(0.90,3.43)$ \\
\hline \multirow[t]{2}{*}{ Age } & $60-74$ & $41.2(29.4,53.8)$ & 1.00 & & 1.00 & & $30.8(24.6,37.5)$ & 1.00 & & 1.00 & \\
\hline & $\geq 75$ & $52.9(27.8,77.0)$ & 1.61 & $(0.55,4.68)$ & 1.31 & $(0.38,4.52)$ & $41.2(24.6,59.3)$ & 1.57 & $(0.75,3.30)$ & 2.03 & $(0.88,4.68)$ \\
\hline \multirow[t]{2}{*}{ Poverty } & no & $45.2(32.5,58.3)$ & 1.00 & & 1.00 & & $36.4(29.0,44.2)$ & 1.00 & & 1.00 & \\
\hline & yes & $39.1(19.7,61.5)$ & 0.78 & $(0.29,2.07)$ & 0.76 & $(0.24,2.40)$ & $23.8(14.9,34.6)$ & 0.55 & $(0.30,1.00)^{*}$ & 0.64 & $(0.33,1.22)$ \\
\hline \multirow[t]{2}{*}{ Empty-nest } & no & $40.5(25.6,56.7)$ & 1.00 & & 1.00 & & $34.8(26.8,43.5)$ & 1.00 & & 1.00 & \\
\hline & yes & $46.5(31.2,62.3)$ & 1.28 & $(0.54,3.02)$ & 1.52 & $(0.56,4.12)$ & $29.1(20.8,38.5)$ & 0.76 & $(0.45,1.32)$ & 0.70 & $(0.38,1.29)$ \\
\hline \multirow[t]{2}{*}{ Illiteracy } & no & $42.9(28.8,57.8)$ & 1.00 & & 1.00 & & $29.7(22.2,38.1)$ & 1.00 & & 1.00 & \\
\hline & yes & $44.4(27.9,61.9)$ & 1.07 & $(0.45,2.54)$ & 0.66 & $(0.20,2.16)$ & $35.5(26.5,45.4)$ & 1.30 & $(0.76,2.23)$ & 0.95 & $(0.50,1.83)$ \\
\hline \multicolumn{12}{|l|}{ Health status } \\
\hline \multirow[t]{2}{*}{ Chronic diseases } & no & - & - & & - & & - & - & & - & \\
\hline & yes & - & - & - & - & - & - & - & - & - & - \\
\hline TTO-value & & - & 1.16 & $(0.14,9.56)$ & 1.07 & $(0.10,11.44)$ & - & 6.78 & $(1.73,26.63)^{* *}$ & 13.56 & $(2.81 \text { to } 65.39)^{* *}$ \\
\hline \multicolumn{12}{|l|}{ Health behaviors } \\
\hline \multirow[t]{2}{*}{ Self-care in TCM } & no & $43.9(28.5,60.3)$ & 1.00 & & 1.00 & & $41.0(30.0,52.7)$ & 1.00 & & 1.00 & \\
\hline & yes & $43.2(28.3,59.0)$ & 0.97 & $(0.41,2.29)$ & 1.03 & $(0.38,2.82)$ & $28.1(21.5,35.6)$ & 0.56 & $(0.32,0.99)^{*}$ & 0.59 & $(0.32,1.09)$ \\
\hline \multirow[t]{2}{*}{ Drinking alcohol } & no & $47.8(35.6,60.2)$ & 1.00 & & 1.00 & & $36.3(29.5,43.6)$ & 1.00 & & 1.00 & \\
\hline & yes & $25.0(7.3,52.4)$ & 0.36 & $(0.11,1.24)$ & 0.36 & $(0.09,1.56)$ & $18.2(29.5,43.6)$ & 0.39 & $(0.18,0.82)^{*}$ & 0.41 & $(0.18,0.91)^{*}$ \\
\hline \multicolumn{12}{|l|}{ Health service } \\
\hline \multirow[t]{3}{*}{ Distance $^{a}$} & $<1 \mathrm{~km}$ & $40.8(27.0,55.8)$ & 1.00 & & 1.00 & & $34.8(26.9,43.2)$ & 1.00 & & 1.00 & \\
\hline & $2-3 \mathrm{~km}$ & $53.8(33.4,73.4)$ & 1.69 & $(0.65,4.41)$ & 1.51 & $(0.54,4.22)$ & $27.3(17.7,38.6)$ & 0.70 & $(0.38,1.30)$ & 0.55 & $(0.28,1.10)$ \\
\hline & $>3 \mathrm{~km}$ & $30.0(6.7,65.2)$ & 0.62 & $(0.14,2.70)$ & 0.60 & $(0.11,3.19)$ & $33.3(16.5,54.0)$ & 0.94 & $(0.39,2.25)$ & 0.83 & $(0.33,2.10)$ \\
\hline \multirow[t]{2}{*}{ Family practice ${ }^{b}$} & no & $45.8(31.4,60.8)$ & 1.00 & & 1.00 & & $38.2(29.6,47.4)$ & 1.00 & & 1.00 & \\
\hline & yes & $40.5(24.8,57.9)$ & 0.81 & $(0.34,1.92)$ & 0.85 & $(0.33,2.17)$ & $26.2(18.7,35.0)$ & 0.57 & $(0.33,0.99)^{*}$ & 0.49 & $(0.27,0.89)^{*}$ \\
\hline
\end{tabular}

Distance to the nearest medical institution

${ }^{b}$ Utilization of family practice service

${ }^{*} P<0.05 ;{ }^{* *} P<0.01$

However, when analysed in different subgroups, the significant predictors were somewhat different. The results of the elders with and without chronic diseases were presented in Table 3. After adjustment, in the subgroup with chronic diseases, the significant predictors included TTO values (OR 13.56, 95\% CI 2.81-65.39), alcohol consumption (OR 0.41; 95\% CI 0.18-0.91) and utilisation of family practice (OR 0.49 , 95\% CI $0.27-$ 0.89 ). No significant variables were independently associated with self-treatment in the subgroup of the elders without chronic disease. As presented in Table 4, having habits of self-care in TCM (OR, 0.39; 95\% CI, 0.18-0.86) and recent alcohol consumption (OR, 0.28; 95\% CI, 0.09-0.82) were found to be associated with a lower probability of self-treatment among the empty-nest elders. In the group of non-empty-nest elders, the older elders (OR 3.10; 95\% CI 1.33-7.22), as well as those in better health status-higher TTO values (OR 9.20; 95\% CI 1.73-48.75), were more likely to selftreat their illness (Table 4).

\section{Discussion \\ Main results}

The present study aimed to explore the determinants associated with self-treatment behaviour among the elderly, focusing on multi-dimensional factors in the rural China context. We found that $35.2 \%$ of the elders with illness in the previous 2 weeks practised self-treatment. The adjusted model showed that self-treatment was strongly associated with better health status, no recent 
Table 4 Comparison of prevalence and prevalence ratios between non-empty-nest and empty-nest elders

\begin{tabular}{|c|c|c|c|c|c|c|c|c|c|c|c|}
\hline \multirow[t]{3}{*}{ variables } & & \multicolumn{5}{|l|}{ Non-empty nest } & \multicolumn{5}{|l|}{ Empty nest } \\
\hline & & \multirow{2}{*}{$\begin{array}{l}\text { Prevalence of } \\
\text { self-treatment } \\
\%(95 \% \mathrm{Cl})\end{array}$} & \multicolumn{2}{|c|}{ Bivariate analysis } & \multicolumn{2}{|c|}{ Multiple regression } & \multirow{2}{*}{$\begin{array}{l}\text { Prevalence of } \\
\text { self-treatment } \\
\%(95 \% \mathrm{Cl})\end{array}$} & \multicolumn{2}{|c|}{ Bivariate analysis } & \multicolumn{2}{|c|}{ Multiple regression } \\
\hline & & & $\overline{\mathrm{OR}}$ & $95 \% \mathrm{Cl}$ & $\overline{\mathrm{OR}}$ & $95 \% \mathrm{Cl}$ & & $\overline{\mathrm{OR}}$ & $95 \% \mathrm{Cl}$ & $\overline{O R}$ & $95 \% \mathrm{Cl}$ \\
\hline \multicolumn{12}{|l|}{ Socio-economic } \\
\hline \multirow[t]{2}{*}{ Gender } & men & $29.1(19.4,40.4)$ & 1.00 & & 1.00 & & $28.6(18.9,40.0)$ & 1.00 & & 1.00 & \\
\hline & women & $41.8(31.9,52.2)$ & 1.75 & $(0.93,3.29)$ & 1.52 & $(0.67,3.39)$ & $39.5(28.4,51.4)$ & 1.63 & $(0.83,3.20)$ & 1.98 & $(0.84,4.64)$ \\
\hline \multirow[t]{2}{*}{ Age } & $60-74$ & $31.4(24.0,39.8)$ & 1.00 & & & & $35.3(27.3,43.9)$ & 1.00 & & 1.00 & \\
\hline & $\geq 75$ & $55.8(37.9,72.8)$ & 2.76 & $(1.29,5.92)^{* *}$ & 3.10 & $(1.33,7.22)^{* *}$ & $23.5(6.8,49.9)$ & 0.56 & $(0.17,1.83)$ & 0.43 & $(0.11,1.68)$ \\
\hline \multirow[t]{2}{*}{ Poverty } & no & $39.5(30.9,48.7)$ & 1.00 & & & & $37.9(28.5,48.0)$ & 1.00 & & 1.00 & \\
\hline & yes & $28.3(16.8,42.3)$ & 0.60 & $(0.30,1.21)$ & 0.76 & $(0.35,1.63)$ & $26.0(14.6,40.3)$ & 0.57 & $(0.27,1.22)$ & 0.68 & $(0.29,1.59)$ \\
\hline \multirow[t]{2}{*}{ Empty-nest } & no & - & - & & - & & - & - & & - & \\
\hline & yes & - & - & - & - & - & - & - & - & - & - \\
\hline \multirow[t]{2}{*}{ Illiteracy } & no & $30.2(21.3,40.4)$ & 1.00 & & 1.00 & & $36.3(26.4,47.0)$ & 1.00 & & 1.00 & \\
\hline & yes & $43.2(32.2,54.7)$ & 1.76 & $(0.95,3.26)$ & 1.15 & $(0.54,2.47)$ & $30.6(19.6,43.7)$ & 0.78 & $(0.39,1.55)$ & 0.54 & $(0.22,1.33)$ \\
\hline \multicolumn{12}{|l|}{ Health status } \\
\hline \multirow[t]{2}{*}{ Chronic diseases } & no & $40.5(25.6,56.7)$ & 1.00 & & 1.00 & & $46.5(31.2,42.3)$ & 1.00 & & 1.00 & \\
\hline & yes & $34.8(26.8,43.5)$ & 0.79 & $(0.38,1.60)$ & 1.37 & $(0.60,3.15)$ & $29.1(20.8,38.5)$ & 0.47 & $(0.23,0.98)^{*}$ & 0.55 & $(0.24,1.23)$ \\
\hline TTO-value & & & 4.46 & $(1.04,19.16)^{*}$ & 9.20 & $(1.73,48.75)^{* *}$ & & 5.05 & $(0.90,28.51)$ & 4.50 & $(0.61,33.04)$ \\
\hline \multicolumn{12}{|l|}{ Health behaviors } \\
\hline \multirow[t]{2}{*}{ Self-care in TCM } & no & $38.5(26.7,51.4)$ & 1.00 & & 1.00 & & $46.3(32.6,60.4)$ & 1.00 & & 1.00 & \\
\hline & yes & $34.8(26.1,44.4)$ & 0.85 & $(0.45,1.61)$ & 0.89 & $(0.43,1.86)$ & $27.3(18.8,37.1)$ & 0.44 & $(0.22,0.87)^{*}$ & 0.39 & $(0.18,0.86)^{*}$ \\
\hline \multirow[t]{2}{*}{ Drinking alcohol } & no & $39.7(31.6,48.3)$ & 1.00 & & 1.00 & & $39.0(30.1,48.4)$ & 1.00 & & 1.00 & \\
\hline & yes & $22.2(10.1,39.15)$ & 0.43 & $(0.18,1.02)$ & 0.48 & $(0.19,1.22)$ & $17.1(6.6,33.6)$ & 0.32 & $(0.12,0.84)^{*}$ & 0.28 & $(0.09,0.82)^{*}$ \\
\hline \multicolumn{12}{|l|}{ Health service } \\
\hline \multirow[t]{3}{*}{ Distance $^{a}$} & $<1 \mathrm{~km}$ & $37.5(28.2,47.5)$ & 1.00 & & 1.00 & & $34.9(24.9,45.9)$ & 1.00 & & 1.00 & \\
\hline & $2-3 \mathrm{~km}$ & $35.6(23.6,49.1)$ & 0.92 & $(0.47,1.79)$ & 0.87 & $(0.42,1.81)$ & $31.8(18.6,47.6)$ & 0.87 & $(0.40,1.89)$ & 0.87 & $(0.35,2.16)$ \\
\hline & $>3 \mathrm{~km}$ & $28.6(8.4,58.1)$ & 0.67 & $(0.20,2.27)$ & 0.73 & $(0.20,2.63)$ & $34.8(16.4,57.3)$ & 1.00 & $(0.37,2.62)$ & 1.00 & $(0.35,2.92)$ \\
\hline \multirow[t]{2}{*}{ Family practice } & no & $41.3(30.4,52.8)$ & 1.00 & & 1.00 & & $39.6(29.5,50.4)$ & 1.00 & & 1.00 & \\
\hline & yes & $32.0(22.9,42.2)$ & 0.67 & $(0.36,1.24)$ & 0.65 & $(0.33,1.26)$ & $25.8(15.5,38.5)$ & 0.53 & $(0.26,1.08)$ & 1.16 & $(0.08,16.51)$ \\
\hline
\end{tabular}

Distance to the nearest medical institution

${ }^{b}$ Utilization of family practice service

${ }^{*} P<0.05 ;{ }^{* *} P<0.01$

alcohol consumption and no utilisation of family practice across the whole sample. However, the predictors, as well as their effect size, differed after stratifying the analysis into different subgroups.

\section{Discussion of the main results \\ Prevalence of self-treatment}

This study showed that $35.2 \%$ of the subjects practised self-treatment. According to the 2013 report of CNHS, the prevalence of self-treatment was much higher (47.2\%) among the elders in western rural China [13]. The proportion of untreated elders is $4.5 \%$, which is similar to the result of CNHS $(1.7 \%$ in western rural China, 2013) [13]. The decline of the prevalence of self-treatment may be partly due to the poverty reduction policies in poverty-stricken areas in the past few years [31]. The poverty reduction policies were found to be related to the increased outpatient rates and the inpatient rate $[35,36]$. Another study conducted in Shanxi, a province in northwestern China in 2016, indicated that $79.4 \%$ of the middle-aged and elderly people had practised selftreatment 12 months before the survey [8]. Most previous studies focused on the behaviour of selfmedication and found that the rates of selfmedication among the elderly range from 20 to $60 \%$ [9]. The difference in methodology, especially the definition of self-treatment and self-medication, might account for the deviation in values to some extent. The differences in the contents of self-treatment/self- 
medication, as well as the diversity of the period of time considered, would result in the differences in the estimation of the prevalence $[9,37]$.

\section{Predictors of the whole sample group}

The prevalence rate of self-treatment was lower among the elders in poverty in the present study. It has been found that elders in middle income group are more likely to self-treat with over-the-counter (OTC) drugs than those in the lowest and highest income groups, which suggested that the elders in China with higher purchasing power preferred for timely self-initiated treatment strategies [38]. One of the possible explanations for the lower possibility of self-treatment for the poor population may be their poor affordability for selfpurchased drug with out-of-pocket money, which cannot be covered by the medical insurance [39]. However, the limitation of the generalizability should be acknowledged, because this definition of poverty cannot be applied in the settings in other countries.

The utilisation of family practice services is strongly associated with the lower possibility of self-treatment in the adjusted model. A cross-sectional study in Spain indicated that visits to the family doctor or other specialists in the last 4 weeks are negatively related to selftreatment, especially in the age group of 45-74 years [37]. It was indicated in a study in China that residents who availed of family practice services perceive higher quality of primary care, including the aspect of first contact-access, continuity, comprehensiveness and coordination [18]. The utilisation of family practice may facilitate rural elders to the necessary medical services and reduce their resorting to self-treatment. However, according to the description analysis of the sample characteristics, only half of elders reported the utilisation of the services in the family practice before. The promotion of family practice is worthy of attention in remote areas.

Better health status is also related to the self-treatment behaviour in the present study, not only for the whole sample, but also in some of the subgroups. Some studies indicated that the prevalence of self-medication is higher among adults with poor self-rated physical and mental health [40], which is different from the result in our study. One of the possible explanations in the rural China context is that the people in remote rural areas are less likely to seek professional medical services if the illness or injury is not severe because of the difficulties of accessing and affording medical service [41]. Thus, rural elders might resort to self-treatment when in a relatively stable health condition, especially in the subgroups of the elders with long-term illness (chronic diseases) and the elders living with the family caregivers (non-empty nest). However, the large 95\% CI of this variable implied that further studies with larger sample sizes were needed to generate the conclusion with higher precision.

The negative association between recent alcohol consumption and self-treatment also contradicted the results of previous studies at home and abroad. The data of the CNHS in 2008 reported a slightly higher proportion of self-treatment among those with drinking habits [17]. The middle-aged and elderly (45-74 years) with recent alcohol consumption in Spain are likely to resort to self-medication [37]. An empirical study in Finland showed that $19.2 \%$ of elders aged over 75 years old use alcohol as self-medication to cope with the heart and vascular disorders, sleep disorders, mental problems and other illnesses [42]. Some studies in alcohol consumption behaviour attributed the difference in drinking patterns to cultural aspects [43]. On the other hand, the cultural factors also played a role in the health-seeking behaviours. Many religious groups reject some or all mainstream health care, such as the Amish, Christian Science, Jehovah's Witness and Islam [44]. Therefore, it can be inferred that there may be some confounding factors related to the subjects' cultural background since our study was conducted in a remote multi-ethnic county.. There was a branch of Islamic faith-Hui people, living in the investigated county, and they have the cultural practice of abstinence from alcohol [45]. nA study in America illustrated that Muslims in the United States interpret their illness as part of God's will, which serves as a barrier for them in seeking medical care [46]. Thus, the cultural background may partly explain the high proportion of self-treatment among elders without the habit of drinking alcohol, who may be the Muslim with specific health beliefs. Further studies were needed to illustrate the relationship between religious beliefs and self-treatment behaviour among the elders.

\section{Comparison between subgroups of elders with and without chronic diseases}

The prevalence of self-reported chronic diseases among the subjects was $74.2 \%$, which was slightly higher than the rate of chronic disease reported in the CNHS in 2013 (65.6\% of the elders aged over 65 in rural areas) [13]. It should be noted that, according to the definition, some of the elders with chronic diseases but in a relatively stable status that needed no any treatment or rest were not included in the population group of the presence of the illness or discomfort in the previous 2 weeks.

The prevalence rate of self-treatment was lower among the elders with chronic diseases, which differed from most previous studies. It was argued in the previous study that people with chronic diseases need regular follow-up visits and usually consume drugs with prescriptions [47]. The difference in prevalence was also 
not significant in the adjusted model. More empirical studies are needed to illustrate the association.

No significant predictors were found in the model of the elders without chronic diseases. A possible explanation is that the self-treatment for acute diseases is common across the population groups with low selfperceived health risks, including the people without chronic diseases [48, 49]. In addition, it should be noted that the small sample size $(N=85)$ in this subgroup may lead to the inadequate power of test, which might result in the false negatives of some variables [50]. Although there was no significant association, the effect size of the variable of gender was similar to that in the whole sample group, and empty-nest elders had higher possibility of self-treatment. Further researches are needed to examine the potential determinants.

As for the subgroup of elders with chronic disease, the risk factors are similar to those of the whole sample, which were discussed above. However, the association was stronger between the utilisation of family practice and the less likelihood of self-treatment, which implied that the family practice utilisation may benefit the elders with chronic disease more on the reduction of selftreatment behaviours. It was reported in a study conducted in southeastern China that among the residents having contracted with family physicians, those with chronic diseases were more likely to utilise the primary care as their usual source of care [18].

\section{Subgroups of empty-nest and non-empty-nest elders}

The most innovative design of this study is the illustration and the comparison between the risk factors of self-treatment among the empty-nest elders and the non-emptynest elders. All independent predictors of self-treatment of empty-nest elders were in the category of health habits, including having the habits of self-care in TCM and no recent alcohol consumption. As for the self-care habit in TCM, on the one hand, people with the habits of self-care may have high perceived susceptibility and are likely to seek professional help instead of the risky self-treatment approaches. Some studies indicated that the self-care practice of some patients with chronic diseases is associated with the high perceived susceptibility of disorders $[48,49]$. On the other hand, elders with the habits of self-care in TCM have higher affinities to TCM [34], and these elders tend to seek medical help in TCM sectors, in which they may be confronted with less barrier during the process of seeing and communicating with doctors compared to the western medicine sectors [51, 52], especially for empty-nest elders without support from younger family caregivers [12]. These findings may explain the lower rate of self-treatment among elders with higher affinities for TCM in this empty-nest subgroup.
As for non-empty-nest elders, those who were no less than 75-year-old or in better health status reported higher rates of self-treatment. The older elders are in the greater vulnerability of health and great need of care [53], and their family caregivers are often equipped with the knowledge of some common health problems and even some skills of healthcare tasks [54]. Given the longterm experience [37] of health problems and the inconvenience to visit doctors in remote areas [55], the older elders are likely to self-treat to cope with their discomforts with the support of their family caregiver, especially when they are in relatively stable health status.

\section{Implications for research and practice}

The unequal prevalence of self-treatment in different population groups suggests the service gaps existing between the elders' actual medical need and the health care delivery system among some older groups in local areas. The identification of the high-risk population of self-treatment would deepen our understanding of the needs of some key populations as well as the inequity in health care delivery among the elderly. Besides, the strong association between the utilisation of family practice services and the lower prevalence of self-treatment implies the potential of family practice in improving the accessibility of the medical help for the rural elders. Currently, the family practice system in China is still in its early stage [56]. A viable model of care [57] and more evidence-based practices are needed to improve the family practice system in China. The findings of this study may provide some clues for the redesign of the service. For example, the result of the subgroup of non-emptynest elders suggested the substantial need of health education for family caregivers of the older elders, such as rational drug use, the training of necessary family caregiver skills and so on $[58,59]$.

However, appropriate self-treatment can bring convenience for individuals and help save medical cost [60], which will also benefit the healthcare system [61]. In consideration of the advantages and risks of selftreatment, as well as rising prevalence of long-term conditions, multiple medicines and increased health care utilisation, the roles of community pharmacists [62] and clinical pharmacists working within the family practice have received increasing interest [63]. Compared with some western countries, the pharmacist system in China is still underdeveloped [64], including the clinical pharmacists in family practice, which should also be attached importance to in developing improvement strategies for primary care.

In all, self-treatment is a critical issue for both health need and health service delivery. Further studies were needed to explore the self-treatment issue in different settings as well as the differences, such as the urban and 
rural areas, as well as the developed and underdeveloped areas.

\section{Limitations}

Nevertheless, the study has several limitations that deserve to highlight. Firstly, the lack of standard definition for self-treatment makes the present results difficult to compare with previous findings [8, 9]. Secondly, the questionnaires did not contain more details of the subjects' self-treatment behaviour, such as the specific form of self-treatment of each respondent, and the type of the medicine used in the self-treatment. Self-reported information may also lead to some reporting bias or recall bias because the majority of the respondents are elders [65]. In addition, the potential seasonal variation in healthy condition as well as in the health-seeking pattern is unavoidable, especially for the elders, which may limit the generalisability of the study.

\section{Conclusion}

In general, self-treatment is a common behaviour among the elders in rural China. Stable health status, no recent alcohol consumption and no utilisation of family practice are associated with a higher probability of selftreatment among rural elders. Older elders in the nonempty nest group were more likely to self-treat, while the empty-nest elders with self-care habits in traditional Chinese medicine were less likely to self-treat. The findings suggest the potential of family practice in improving the access to medical care for rural elders. The identification of the determinants of some specific population groups may provide clues for the improvement strategies of healthcare delivery system for the rural elders. Further studies on self-treatment patterns and decision-making mechanisms are needed to elucidate the potential need and access barriers of healthcare among the rural elders.

\section{Abbreviations}

ADRs: Adverse drug reactions; CNHS: China National Health Survey; LMICs: Low and middle income countries; TCM: Traditional Chinese medicine; TTO: Time trade-off; OTC: over-the-counter

\section{Acknowledgements}

We sincerely thank to all the government officers and residents involved in this study. This work wouldn't have been possible without their generous assistance. Besides, we thank all the investigators in the household survey.

\section{Authors' contributions}

WCX, ZL and LZ drafted the outline of this study. All co-authors were responsible to collect the data. ZL performed data management. WCX and ZJP performed the data analysis. All co-authors critically reviewed the first results. WCX drafted the first manuscript, and ZL, RBH, ZJP, LZ gave critical feedback. All authors read and approved the final manuscript.

\section{Funding}

This work was funded by National Natural Science Foundation of China (Grant NO: 71734003). The funder had no role in study design, data collection and analysis, or manuscript preparation.

\section{Availability of data and materials}

The datasets used and analysed during the current study are available from the corresponding author on reasonable request.

Ethics approval and consent to participate

The study was approved by the ethics committee of Tongji Medical College, Huazhong University of Science and Technology (IORG No: IORG0003571). Informed consent was obtained from the participants enrolled in the household survey, and the residents were assured that their participation was voluntary and they could withdraw from the study at any time.

Consent for publication

Not applicable.

\section{Competing interests}

The authors declare that they have no competing interests.

Received: 23 September 2019 Accepted: 27 February 2020

Published online: 12 March 2020

\section{References}

1. Araujo de Carvalho I, Epping-Jordan J, Pot AM, Kelley E, Toro N, Thiyagarajan JA, et al. Organizing integrated health-care services to meet older people's needs. Bull World Health Organ. 2017;95(11):756-63.

2. Wodchis WP, Dixon A, Anderson GM, Goodwin N. Integrating care for older people with complex needs: key insights and lessons from a seven-country cross-case analysis. Int J Integr Care. 2015;15:e021.

3. Jacobs B, Ir P, Bigdeli M, Annear PL, Van Damme W. Addressing access barriers to health services: an analytical framework for selecting appropriate interventions in low-income Asian countries. Health Policy Plan. 2012;27(4): 288-300.

4. Gilson L. Trust in health care: theoretical perspectives and research needs. J Health Organ Manag. 2006;20(5):359-75.

5. Holroyd E. Health-seeking behaviors and social change: the experience of the Hong Kong Chinese elderly. Qual Health Res. 2002;12(6):731-50.

6. Li Z, Pan ZJ, Zhang L, He RB, Jiang S, Xu CZ, et al. End-of-life cost and its determinants for cancer patients in urban China: a population-based retrospective study. BMJ Open. 2019;9(3):e026309.

7. Jafari F, Khatony A, Rahmani E. Prevalence of self-medication among the elderly in Kermanshah-Iran. Global J Health Sci. 2015;7(2):360-5.

8. Wang R, Ma CJ, Jiang K, Li M, Ma SG. Descriptions of self-treatment for the middle-aged and elderly in Shanxi, China. PLoS One. 2018;13(6):e0198554.

9. Jerez-Roig J, Medeiros LF, Silva VA, Bezerra CL, Cavalcante LA, Piuvezam G, et al. Prevalence of self-medication and associated factors in an elderly population: a systematic review. Drugs Aging. 2014;31(12):883-96.

10. Bennadi D. Self-medication: a current challenge. J Basic Clin Pharm. 2013; 5(1):19-23.

11. WHO. The role of the pharmacist in self-care and self-medication. The Netherlands: WHO; 1998.

12. Mortazavi SS, Shati M, Khankeh HR, Ahmadi F, Mehravaran S, Malakouti SK Self-medication among the elderly in Iran: a content analysis study. BMC Geriatr. 2017;17(1):198.

13. NHFPC. An analysis report of the fifth National Health Services Survey in China, 2013. Beijing: NHFPC; 2015.

14. Jiang $Y$, Wang $Y, L i$ Y, Wang $X$, Ma C, Ma S. Prevalence, characteristics, and cost of self-treatment in the middle-aged and elderly: observations from Henan, China. Public Health. 2015;129(5):597-600.

15. Meranius MS, Hammar LM. How does the healthcare system affect medication self-management among older adults with multimorbidity? Scand J Caring Sci. 2016;30(1):91-8.

16. Vali L. An investigation on inappropriate medication applied among elderly patients. World Appl Sci J. 2012;16:819-25.

17. Li YF, Rao KQ, Ren XW. Use of and factors associated with self-treatment in China. BMC Public Health. 2012;12:995.

18. Kuang L, Liang Y, Mei J, Zhao JG, Wang YT, Liang HL, et al. Family practice and the quality of primary care: a study of Chinese patients in Guangdong Province. Fam Pract. 2015;32(5):557-63.

19. Beach SR, Schulz R. Family caregiver factors associated with unmet needs for care of older adults. J Am Geriatr Soc. 2017;65(3):560-6. 
20. Liu $L$, Guo Q. Life satisfaction in a sample of empty-nest elderly: a survey in the rural area of a mountainous county in China. Qual Life Res. 2008;17(6): 823-30.

21. Wolff $J$, Roter DL. Family presence in routine medical visits: a metaanalytical review. Soc Sci Med. 2011;72(6):823-31.

22. Lavretsky $\mathrm{H}$. The role of family caregivers and inappropriate medication use in the community-dwelling older adults with dementia. Aging Health. 2012; 8(5):457-60.

23. Zhou CC, Ji CM, Chu J, Medina A, Li CC, Jiang S, et al. Non-use of health care service among empty-nest elderly in Shandong, China: a crosssectional study. BMC Health Serv Res. 2015;15:294.

24. Chung VCH, Ma PHX, Lau CH, Wong SYS, Yeoh EK, Griffiths SM. Views on traditional Chinese medicine amongst Chinese population: a systematic review of qualitative and quantitative studies. Health Expect. 2014;17(5):622-36.

25. Zhong Z, Zhiying S, Ding S, Zheng F, Duan Y, Luo A. Status for selfmedication based on bibliometric study in China. J Cent South Univ (Med Sci). 2017:42:434-9.

26. Zhang $X, Y u$ B, He T, Wang P. Status and determinants of health services utilization among elderly migrants in China. Glob Health Res Policy. 2018;3:8.

27. A brief introduction of Sinan County. http://www.sinan.gov.cn/zjsn/snjj/. Accessed 1 Feb 2020.

28. Bulletin on the Main data of the Sixth Population Census in Tongren Area in 2010. http://202.98.195.171:81/c7/20170215/i159.html. Accessed 1 Feb 2020.

29. County TgoS. Administrative division of Sinan County. http://www.sinan.gov. cn/zjsn/xzqh/201709/t20170930_15968328.html. Accessed 1 Feb 2020.

30. Lu C. Poverty and development in China: alternative approaches to poverty assessment. Abingdon: Routledge; 2013.

31. The State Council. Notice on the work plan for establishing documents and approving CARDS for poverty alleviation and development. The State Council. http://www.cpad.gov.cn/art/2014/4/11/art_50_23761.html. Accessed 1 Feb 2020.

32. Maor $Y$, King M, Olmer L, Mozes B. A comparison of three measures: the time trade-off technique, global health-related quality of life and the SF-36 in dialysis patients. J Clin Epidemiol. 2001;54(6):565-70.

33. Liu GG, Wu H, Li M, Gao C, Luo N. Chinese time trade-off values for EQ-5D health states. Value Health. 2014;17(5):597-604.

34. Chung VCH, Wong SYS, Wang HHX, Wong MCS, Wei XL, Wang JJ, et al. Use of traditional and complementary medicine as self-care strategies in community health centers cross-sectional study in Urban Pearl River Delta Region of China. Medicine. 2016;95(23):e3761.

35. Zou Q, He X, Li Z, Xu W, Zhang L. The effects of poverty reduction policy on health services utilization among the rural poor: a quasi-experimental study in central and western rural China. Int J Equity Health. 2019;18(1):186.

36. O'Donnell O. Access to health care in developing countries: breaking down demand side barriers. Cad Saude Publica. 2007;23(12):2820-34.

37. Niclos G, Olivar T, Rodilla V. Factors associated with self-medication in Spain: a cross-sectional study in different age groups. Int J Pharm Pract. 2018;26(3): 258-66.

38. Chang J, Wang Q, Fang Y. Socioeconomic differences in self-medication among middle-aged and older people: data from the China health and retirement longitudinal study. BMJ Open. 2017;7(12):e017306.

39. Liang T. Health security underpinning: local practice and future prospect of medical assistance system construction. Chin J Health Policy. 2017;10(3):47-53.

40. Kamran A, Sharifirad G, Shafaeei Y, Mohebi S. Associations between Selfmedication, Health Literacy, and Self-perceived Health Status: A Community-Based Study. Int J Prev Med. 2015;6:66.

41. Li JJ, Shi LY, Liang HL, Ding G, Xu LZ. Urban-rural disparities in health care utilization among Chinese adults from 1993 to 2011. BMC Health Serv Res. 2018;18:102.

42. Aira M, Hartikainen S, Sulkava R. Drinking alcohol for medicinal purposes by people aged over 75: a community-based interview study. Fam Pract. 2008; 25(6):445-9.

43. Li HZ, Rosenblood L. Exploring factors influencing alcohol consumption patterns among Chinese and Caucasians. J Stud Alcohol. 1994;55(4):427-33.

44. Herrera CD. Disputes between state and religion over medical treatment for minors. J Church State. 2005:47(4):823-39.

45. Al-Ansari B, Thow AM, Day CA, Conigrave KM. Extent of alcohol prohibition in civil policy in Muslim majority countries: the impact of globalization. Addiction. 2016;111(10):1703-13.
46. Padela Al, Curlin FA. Religion and disparities: considering the influences of Islam on the health of American Muslims. J Relig Health. 2013;52(4):1333-45.

47. Domingues PHF, Galvao TF, de Andrade KRC, Araujo PC, Silva MT, Pereira MG. Prevalence and associated factors of self-medication in adults living in the Federal District, Brazil: a cross-sectional, population-based study. Epidemiol Serv Saude. 2017;26(2):319-30.

48. Dehghani-Tafti A, Mazloomy Mahmoodabad SS, Morowatisharifabad MA, Afkhami Ardakani M, Rezaeipandari H, Lotfi MH. Determinants of self-care in diabetic patients based on health belief model. Global J Health Sci. 2015; 7(5):33-42.

49. Larki A, Tahmasebi R, Reisi M. Factors Predicting Self-Care Behaviors among Low Health Literacy Hypertensive Patients Based on Health Belief Model in Bushehr District, South of Iran. Int J Hypertens. 2018;2018:9752736.

50. Burke JF, Sussman JB, Kent DM, Hayward RA. Three simple rules to ensure reasonably credible subgroup analyses. BMJ. 2015;351:h5651.

51. Zhang JJ, Verhoef MJ. Illness management strategies among Chinese immigrants living with arthritis. Soc Sci Med. 2002;55(10):1795-802.

52. Green G, Bradby H, Chan A, Lee M. "We are not completely westernised": dual medical systems and pathways to health care among Chinese migrant women in England. Soc Sci Med. 2006;62(6):1498-509.

53. Kuluski K, Gill A, Naganathan G, Upshur R, Jaakkimainen RL, Wodchis WP. A qualitative descriptive study on the alignment of care goals between older persons with multi-morbidities, their family physicians and informal caregivers. BMC Fam Pract. 2013;14:133.

54. Bassah N, Ubenoh U, Palle J. An exploratory study of the knowledge and practices of family caregivers in the care of the elderly at home in the Buea Health District, Cameroon. J Gerontol Geriatr Res. 2018;7(473):2.

55. Ansari M. Sociobehavioral aspects of medicines use in developing countries. Social and administrative aspects of pharmacy in low-and middle-income countries. Amsterdam: Elsevier; 2018. p. 15-33.

56. Pan $\mathrm{G}$, Yang $\mathrm{Y}$. The current situation of family doctor team services mode. Chin Gen Pract. 2017;20(28):3457-62.

57. Bhattacharyya O, Delu Y, Wong ST, Bowen C. Evolution of primary care in China 1997-2009. Health Policy. 2011;100(2-3):174-80.

58. Reinhard SC, Given B, Petlick NH, Bemis A. Supporting family caregivers in providing care. Patient safety and quality: An evidence-based handbook for nurses. Rockville: Agency for Healthcare Research and Quality (US); 2008.

59. Lau DT, Kasper JD, Hauser JM, Berdes C, Chang CH, Berman RL, et al. Family caregiver skills in medication management for hospice patients: a qualitative study to define a construct. J Gerontol B Psychol Sci Soc Sci. 2009;64(6):799-807.

60. Noone J, Blanchette CM. The value of self-medication: summary of existing evidence. J Med Econ. 2018;21(2):201-11.

61. Hughes CM, McElnay JC, Fleming GF. Benefits and risks of self medication Drug Saf. 2001;24(14):1027-37.

62. You JH, Wong FY, Chan FW, Wong EL, Yeoh EK. Public perception on the role of community pharmacists in self-medication and self-care in Hong Kong. BMC Clin Pharmacol. 2011:11:19.

63. Cardwell K, Smith SM. Clinical pharmacists working within family practice: what is the evidence? Fam Pract. 2018:35(2):120-1.

64. Fang $Y$, Yang SM, Zhou ST, Jiang MH, Liu J. Community pharmacy practice in China: past, present and future. Int J Clin Pharm Net. 2013;35(4):520-8.

65. Knauper B, Carriere K, Chamandy M, Xu Z, Schwarz N, Rosen NO. How aging affects self-reports. Eur J Ageing. 2016;13(2):185-93.

\section{Publisher's Note}

Springer Nature remains neutral with regard to jurisdictional claims in published maps and institutional affiliations. 